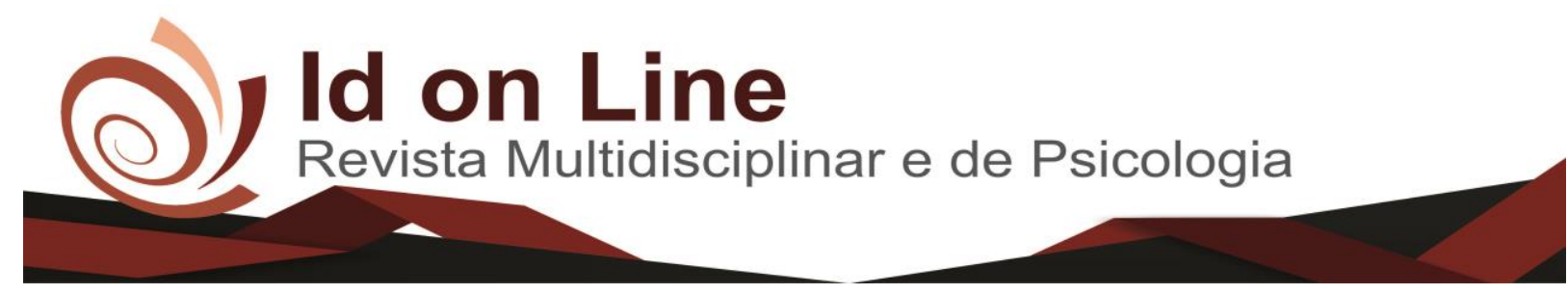

Comment

\title{
Transtorno do Déficit de Atenção e Hiperatividade - TDAH: Desafios e Possibilidades no Espaço Escolar
}

\author{
Cineide Maria Benício ${ }^{1}$; Aurelania Maria de Carvalho Menezes ${ }^{2}$
}

Resumo: O presente trabalho abordou a vida do aluno com TDAH - Transtorno de Déficit de Atenção e Hiperatividade. Trata-se de uma pesquisa qualitativa, de procedimento bibliográfico, com base em estudos relevantes de teóricos conceituados e objetivou compreender e explicar elucidativamente as questões inerentes ao TDAH. Buscou conhecer os problemas enfrentados pelos alunos com o transtorno, suas dificuldades em aprendizagem devido sua incapacidade de concentração, os desafios e as possibilidades que o professor enfrenta dentro da sala de aula para fazer com que este aluno desenvolva no aprendizado. Evidenciou-se que a participação da família e da escola em trabalho conjunto para a efetivação do ensino e aprendizado gera resultados importantes e positivos para o sujeito com TDAH. A importância do diagnóstico logo nas series iniciais pode contribuir para um tratamento exitoso. Mostrou algumas práticas pedagógicas de professores que lindam na sala de aula com o aluno com TDAH e a rica colaboração do professor no processo da aprendizagem da criança.

Palavras Chaves: Transtorno de Déficit de Atenção e Hiperatividade, Aprendizagem, Práticas Pedagógicas.

\section{Attention Deficit Hyperactivity Disorder - ADHD: Challenges and Possibilities in School Space}

\begin{abstract}
The present work addressed the life of the student with ADHD - Attention Deficit Hyperactivity Disorder. It is a qualitative research, of a bibliographic procedure, based on relevant studies of theoretical concepts and aims to understand and explain elucidatively the issues inherent to ADHD. He sought to know the problems faced by the students with the disorder, their difficulties in learning due to their inability to concentrate, the challenges and the possibilities that the teacher faces within the classroom to make this student develop in learning. It was evidenced that the participation of the family and the school in joint work for the accomplishment of teaching and learning generates important and positive results for the subject with ADHD. The importance of diagnosis early in the series can contribute to a successful treatment. It showed some pedagogical practices of teachers that surround in the classroom with the student with ADHD and the rich collaboration of the teacher in the process of learning the child.
\end{abstract}

Keywords: Attention Deficit Hyperactivity Disorder, Learning, Pedagogical Practices.

\footnotetext{
${ }^{1}$ Graduanda do Curso de Licenciatura em Pedagogia pela Faculdade de Ciências Humanas do Sertão Central - FACHUSC.

Contato: cineidebenicio@gmail.com;

${ }^{2}$ Graduação em Pedagogia - AEDS. Professora da ESCOLA MUNICIPAL VALDEMAR SOARES DE MENEZES. Professora da FACHUSC

- Faculdade de Ciências Humanas do Sertão Central.
} 


\section{Introdução}

São muitos os problemas encontrados atualmente dentro de um espaço escolar e vão da indisciplina à violência de fato. Mas existem outros públicos dentro das instituições de ensino, com seus comportamentos que independem do querer ser ou fazer.

Sãos deficiências ou transtornos que a escola deve acolher em seu ambiente e atendêlos conforme suas especificidades.

O Transtorno de Déficit de Atenção e Hiperatividade - TDAH é atualmente um transtorno bastante comum encontrado nas escolas e por isso mesmo tem gerado debates, discussões e estudos entre educadores e estudiosos.

O TDAH não é uma doença, mas uma síndrome e por isso mesmo não fala-se em cura. Doença é um estado em que o corpo se encontra, causada por situações ou agentes específicos que podem ser eliminados e assim retornar ao normal. O TDAH tem um conjunto de sintomas, com causas múltiplas, fatores neurobiológicos, pessoais e ambientais. Ser ou não uma doença, o que importa ao transtornado ou seus pais é como lidar e com os sintomas e tratá-los.

Este tema foi escolhido devido à sua importância dentro do universo escolar e pelo fato de muitas crianças com TDAH não receberem o diagnóstico, impossibilitando de serem atendidas corretamente. Também com a observação e investigação do trabalho árduo do professor em lidar com a diversidade e o fato de que, muitas vezes, não tem o conhecimento e a distinção do que realmente seja este transtorno e em consequência disso, age de forma precipitada ou incorreta. Um outro ponto decisivo para a escolha do tema é saber que existem preconceitos e incompreensão com o educando com TDAH.

O presente trabalho visa o conhecimento científico do referido transtorno para entender, conhecer e analisar a qualidade do ensino e aprendizagem dos educandos com TDAH. Mas, diante das dificuldades e múltiplas facetas do TDAH, e que para se alcançar esses estudantes é necessário ter um conhecimento acerca do problema, como é possível analisar de forma assertiva partindo dos referenciais educacionais para trabalhar com alunos com TDAH, já que este transtorno é diagnóstico exclusivo dos profissionais da psicologia e médica? Sendo assim, objetiva também conhecer práticas pedagógicas usadas para facilitar a aprendizagem.

Ao contrário dos que muitos pensam, mesmo sendo o TDAH um tema de diagnóstico exclusivo dos profissionais de psicologia e médica, é possível que o âmbito da educação 
contribua no diagnóstico e até mesmo no tratamento do transtorno do déficit de atenção e hiperatividade. Partindo deste primeiro ponto do diagnóstico, os professores poderão com muita propriedade ajudar no desenvolvimento cognitivo da criança, jovem ou adulto.

Compreendendo que o TDAH é de natureza complexa e de difícil equalização, pode-se dizer que apesar dos limites e das inúmeras interpretações sobre o fenômeno, existem formas e estratégias gerais adequadas para os educadores melhor atuarem com a síndrome.

A escola enquanto primeiro espaço para construção do conhecimento das crianças enfrenta desafios e possibilidades na educação especial, na formação de professores qualificados na área, na conjunção de escola e da família.

Mesmo sendo um tema em evidência, por falta de conhecimento, o aluno com TDAH é vitima de preconceitos pelos colegas, professores e até pela própria família, por isso, é tão importante ter o conhecimento científico do transtorno, que é reconhecido pela OMS Organização Mundial da Saúde.

A metodologia empregada para o desenvolvimento do tema é bibliográfico e algumas observações informais. Foram realizados estudos em obras de teóricos envolvidos com o tema, como Amorim (2012), Barkley (2002), Toneolotto (2003), Benczin (2000), entre outros, assim como a própria OMS.

Esse trabalho de conclusão de curso foi dividido em 6 etapas. Com a introdução do assunto em destaque e seus objetivos, contendo a justificativa para a escolha do tema. Segue outra etapa falando do diagnóstico como um transtorno e não como doença. Uma outra etapa fala do tratamento com profissional adequado. Relata também do apoio educacional necessário para amenizar a síndrome. Salienta a importância da parceria escola e família com os cuidados com a pessoa com TDAH. Culmina o trabalho com as conclusões através de estudos e observações.

\section{Da Definição ao Diagnóstico}

Segundo a Associação Brasileira de Déficit de Atenção - ABDA, o TDAH é um transtorno neurobiológico, de causas genéticas, que aparece na infância e frequentemente 
acompanha o individuo por toda a sua vida. Ele se caracteriza por sintomas de desatenção, inquietude e impulsividade.

Para Amorim (2012):

TDAH não é uma "doença", no sentido literal de algo que se "pega", para depois ser tratado e resolvido definitivamente. O TDAH é uma síndrome - um conjunto de sintomas - com causas multi-fatoriais, entre eles a base orgânica neurológica, a história pessoal de desenvolvimento familiar, o estilo de vida, as circunstâncias presentes, entre outras. Por isto, não existe uma solução única e definitiva para os problemas. Apesar desta complexidade, há diversas alternativas de tratamento, que podem aliviar os sintomas, melhorando muito a qualidade de vida. Mesmo que não possa ser "curado", o TDAH pode - e deve - ser bem gerenciado. (AMORIM, 2012)

Estudos científicos mostram que pessoas com TDAH tem alteração na região frontal e as suas conexões com o resto do cérebro. Essa região do cérebro é responsável pela inibição do comportamento, isto significa controlar ou inibir comportamentos inadequados, capacidade de prestar atenção, memória, autocontrole, organização e planejamento. (ABDAH, 2010)

O TDAH não é uma invenção da cabeça de alguém que quis conseguir uma desculpa para sua falta de pontualidade, de organização, de comprometimento como algumas pessoas que convivem com pessoas com TDAH pensam, mas é comprovado cientificamente e reconhecido pela OMS que este transtorno existe sim e causa alterações na região do lombo.

São diversos os sintomas que identificam o TDAH, como esclarece Barkley (2002):

O Transtorno do Déficit de Atenção e Hiperatividade são identificados pelos seguintes sintomas: dificuldade de prestar atenção a detalhes ou errar por descuido em atividades escolares e de trabalho; dificuldade para manter atenção em atividades lúdicas; parecer não escutar quando lhe dirigem a palavra; não seguir instruções e não terminar tarefas escolares, domesticas ou deveres profissionais; mudar constantemente de uma atividade para outra sem terminar nenhuma; dificuldade em organizar tarefas e atividades; evitar ou relutar em envolver-se em tarefas que exijam esforço mental constante, fuga de brincadeiras que exijam muita concentração; perder coisas necessárias para tarefas ou atividades; ser facilmente distraído por estímulos alheios a tarefa e apresentar esquecimentos em atividades diárias. (BARKLEY, 2002).

Todos estes sintomas parecem comum para qualquer pessoa, mas, a avaliação dos mesmos dar-se a partir da continuidade e intensidade em que se apresenta, por ser características que muitos tem, se não tiver um determinado cuidado com essa investigação pode ser facilmente confundida com um mero defeito ou um determinado momento que se pode estar atravessando. 
Para avaliar os sintomas, Tonelotto (2003) fala que o profissional que avalia deve incluir entrevista com crianças, pais e professores, além de observação diretamente na escola e no lar.

As crianças e jovens com TDAH sofrem muito preconceito nas escolas, dentro de sua própria família e por falta de conhecimento são tachados como burros, indisciplinados, não quer nada com a vida, vive com a cabeça no mundo da lua, encrenqueiro por ser agitado e mexer com todos os colegas na sala de aula.

Por isso a necessidade de uma avaliação logo nos anos iniciais até mesmo para que não venha sofrer constrangimentos e uma má formação escolar na jornada estudantil, tendo em vista que o TDAH não é uma fase temporária, mas, que acompanha até a vida adulta, em que futuramente poderá apresentar problemas depressivos, alteração de humor, atrativos ao uso de drogas, dificuldades no convívio social, caso não seja diagnosticado na infância.

A partir dos 3 ou 4 anos já é possível identificar alguns comportamentos significativos, ou seja, na fase antes do período escolar, mas, é quando a criança entra na escola que aprende a inibir um comportamento frente a um comando.

Benczin (2000) mostra que os instrumentos mais empregados nos Brasil é a investigação da atenção, que são os questionários. Esses questionários devem incluir todos que convive no meio em que se encontra o portador, inclusive com o próprio portador, embora ele irá apresentar grandes dificuldades de se expressar, dependendo da dificuldade de se diagnosticar é possível contar com exames de imagens feitos no cérebro, estes mostraram evidencias de disfunção em pessoas com TDAH (no córtex pré-frontal, núcleos da base, cerebelo e outras).

Para um bom resultado no diagnóstico conta-se com a participação de vários profissionais, primeiro a família e a escola devem detectar os sintomas, segundo devem ser encaminhado para o psicólogo, para que faça testes psicológicos, terceiro pode se contar com a ajuda do psiquiatra e constatar que realmente a pessoa é portadora do TDAH, para o tratamento ela poderá contar ainda com a ajuda de fonoaudiólogos, psicopedagogo e educadores.

Apesar de a educação inclusiva, sob a forma da legislação que rege sobre a Educação Especial, nada falar a respeito desses casos ou ainda não abranger de forma clara as crianças com dificuldades de aprendizagem ainda desconhecidas ou sobre as quais pouco se sabe, como é o caso do TDAH, há necessidade de que essas crianças devam ser tratadas de modo especial, tendo sua educação diferenciada de modo que a aprendizagem seja alcançada no seu ritmo. Em 
geral, sob olhar comum, elas são tidas como mal educadas, preguiçosas, incapazes intelectualmente, e, portanto, agredidas em seu direito de ser e de amar.

\section{TDAH e o Tratamento Profissional para Amenizar o Transtorno}

No início da década de 1980 aconteceu a publicação do DSM-III (Manual Diagnóstico e Estatístico dos Distúrbios Mentais, Terceira Edição) através da Sociedade Americana de Psiquiatria, sendo posteriormente re-conceituado a partir do DSM II, e nessa ocasião o nome Transtorno de Déficit de Atenção surgiu pela primeira vez.

Essa nova definição para o distúrbio deixava claro que o ponto central do problema era justamente a dificuldade de manter a atenção (Phelan, 2005). Quando o DSM III foi revisado em 1987 o transtorno foi classificado com base na presença ou ausência de impulsividade e hiperatividade (Barkley, 1997, 1998) e o nome do distúrbio foi substituído pelo Transtorno de Déficit de Atenção e Hiperatividade (TDAH).

Os sistemas classificatórios modernos utilizados em psiquiatria, CID-10 e DSM-IV, utilizam nomenclaturas diferentes (Transtorno de Déficit de Atenção/Hiperatividade no DSMIV e Transtornos Hipercinéticos na CID-10), entretanto, apresentam mais similaridades que diferenças nas diretrizes diagnósticas do transtorno (Rohde e Halpern, 2004).

Antes de qualquer tratamento, primeiro deve-se chegar a um diagnóstico. Tendo observado o desenvolvimento do transtorno, é possível tratar e amenizar a partir de intervenções psicológica, pedagógica, médica e principalmente o psicopedagogo. Levando em consideração as múltiplas facetas em que ele se apresenta e as suas especificidades.

Conforme Benczik (2002) o trabalho do psicopedagogo é muito importante, pois auxilia, atuando diretamente sobre a dificuldade escolar apresentada pela criança, suprindo a defasagem, reforçando o conteúdo, possibilitando condições para que novas aprendizagens ocorram, e orientando professores.

Durante algumas décadas o transtorno do déficit de atenção era tratado somente de forma medicamentosa em que se buscava controlar os sintomas comportamentais, por se tratar de causas neurobiológicas, onde é comprovado cientificamente que existe um distúrbio na região frontal do cérebro, porém, a ciência vem avançando nas suas pesquisas e grandes 
descobertas significativas feita por vários profissionais, vem mostrando que o tratamento terapêutico, o acompanhamento dos pais e professores, tem contribuído para que o Déficit de Atenção com Hiperatividade dê passos significativos no seu processo de aprendizagem.

Diferente do que já foi abordado anteriormente, o Neurologista Dr. Dinizar Filho (2003), especialista em Hiperatividade, refere-se ao transtorno como uma doença, em uma de suas entrevistas e aborda alguns tratamentos:

[....] Por ser uma doença que acaba desenvolvendo um aspecto comportamental, é como qualquer doença, o tratamento é diferencial para cada nível de hiperatividade. Há casos que exigem só a terapia comportamental. Outros casos a partir de maior grau de compreensão da criança em relação ao problema, ela terá que ter condições de conviver com essa doença, desenvolver um processo de auto-controle, daí a necessidade de terapia como apoio. De modo geral é necessário a psicoterapia de apoio nesse tratamento e a pessoa poderá conviver com isso sem que haja prejuízo para ela, nem para o ambiente. Existem casos intermediários da doença em que se pode optar por algum tipo de tratamento medicamentoso, num grau menor, juntamente com terapia comportamental. E há casos extras em que é necessário a utilização de psicofármacos específicos para a questão. Cada grau tem a sua avaliação, seu manuseio e sua forma de conduzir. Os medicamentos mais utilizados no controle dos sintomas relacionados com o TDAH são os psicoestimulantes. A hiperatividade ocorre por falta de regulação nos neuro-transmissores. Nós temos no lobo frontal, na parte anterior do cérebro, uma área que desenvolve o equilíbrio entre a percepção, a estimulação ambiental e a capacidade de resposta neuro-orgânica a tudo isso. Quando ocorre uma deficiência na produção de determinadas substâncias como a dopamina, acarreta uma falta de equilíbrio nesse funcionamento, a criança não tem um processo de limitação, então os psicoestimulantes estimulam a produção desses neurotransmissores que estão deficientes. (FILHO, 2003)

Podemos perceber que existe uma grande variável na apresentação dos sintomas e dessa forma não existe um único tratamento, há uma diversidade de profissionais e cada um com metodologias diferentes. Desde o pedagogo, com suas atividades lúdicas ao Neurologista ou Psiquiatra com seus medicamentos.

As atividades lúdicas, como jogos, exercícios sensório motores, jogos intelectuais como matemáticos, que existe regras, limites, o perder e o ganhar, é uma das formas que ajuda bastante no desenvolvimento do aluno com TDAH, aonde o mesmo não está condicionado a regras e limites pela sua impulsividade, tratando-se aqui dos casos de hiperatividade, poderá possibilitar a criança a perceber suas limitações e controlar seus impulsos, aprendendo a esperar a sua vez. Já no caso do desatento estas atividades também poderão ser bastante eficazes no aprendizado desta criança, por se tratar de atividades dinâmicas, com tempos curtos, já que a 
criança desatenta tem consigo uma grande dificuldade em se concentrar nas atividades longas e rotineiras.

A Ritalina é a alternativa medicamentosa mais comum para o TDAH. Muitas dúvidas sobre medicação são comuns quando se tem suspeita ou um diagnóstico já confirmado do transtorno. A faixa preta sempre assusta. É uma reação extremamente comum, devido a perguntas não respondidas e falta de informação. É preciso conhecer mais sobre o TDAH em si, todos os tipos de tratamentos medicamentosos e também sem uso de remédios. Vale ressaltar que toda forma de tratamento vai depender de um diagnóstico correto, e que nem tudo é déficit de atenção, por isso os pais e professores que estão diretamente ligados a criança devem ter todo o cuidado ao rotulá-lo, pode acontecer que a criança esteja atravessando uma fase difícil por alguma questão social ou afetiva na família e ser confundido com um transtorno.

\section{A Contribuição dos Professores no Processo de Aprendizagem do Aluno com TDAH}

Percebe-se que a maior responsabilidade está sobre o professor por ter o papel de ensinar, de levar o aluno a adquirir o conhecimento, a desenvolver seu intelecto, seu próprio pensamento, aí se encontra o desafio do professor, sendo que a pessoa com TDAH falta a capacidade de concentração, e não lhe falta a inteligência, mas o seu aprendizado será mais lento considerando a forma que lhe será apresentado.

Para Dupal e Stoner (2007):

Ao analisarmos a aprendizagem e o desempenho em sala de aula de criança TDAH, precisamos ter em mente algumas variáveis, que vão desde suas habilidades acadêmicas básicas ate os comportamentos observáveis que interferem potencialmente no desempenho daquele aluno. (DUPAL e STONER, 2007, p.154).

Este com certeza é um trabalho árduo para o professor conquistar a atenção dos seus alunos e quando se trata especificamente da falta desta capacidade a dificuldade dobra, embora não é um trabalho impossível, desde que o professor tenha conhecimento do seja o TDAH e saiba identificar no aluno os sintomas, poderão dar passos significativos no ensino aprendizado deste aluno.

Para Estanislau e Bressan (2014): 
O educador tem importante papel e real responsabilidade em relação ao processo de aprendizagem de seus alunos, torna-se extremamente importante que ele esteja atento para identificar o mais rápido possível qualquer problema que o possa comprometer o aprendizado da criança. (ESTANISLAU e BRESSAN, 2014, p.25)

O TDAH é uma das grandes dificuldades no processo de ensino e aprendizagem enfrentadas pelas escolas, tendo em vista que nem sempre ocorrem revisões de conceitos e aperfeiçoamentos por parte dos docentes.

A desinformação sobre o assunto leva os educadores muitas vezes a cometer equívocos quanto aos métodos que utiliza tanto no diagnóstico quanto no modo de trabalhar com esses alunos. Mattos (2007) relata que, para lidar com uma criança com esse transtorno, antes de qualquer coisa, o professor necessita conhecer a síndrome e saber diferenciá- lo de má educação, indolência ou simplesmente preguiça. Ele terá que conseguir equilibrar as necessidades dos demais estudantes com a dedicação de que uma criança com TDAH necessita o que pode ser difícil com uma turma numerosa.

A aprendizagem é um processo ao qual toda criança vai se apropriando conforme a sua convivência com seu grupo social, pois para que a criança possa sempre aprender ela necessita estar sempre interagindo com outras pessoas, por que, conforme Pantoja (2005):

A aprendizagem é um processo interno e pessoal, que ocorre dentro do sujeito. No entanto, só as ações manifestas ou os comportamentos do sujeito (o que ele faz, diz ou produz) permitem a um observador externo concluir se houve ou não aprendizagem, na extensão e na competência desejáveis. Para que haja aprendizagem é necessária a ação do sujeito sobre o objeto de conhecimento. (PANTOJA, 2005, p.35).

Repensar as práticas metodológicas e inová-las quando preciso é uma das formas viáveis dentro do processo ensino-aprendizagem de atender os alunos levando em conta as diversas dificuldades de aprendizagem apresentadas.

\section{A Ação Conjunta da Escola e da Família no Tratamento do TDAH}

A escola e a família devem caminhar de mãos dadas no processo do ensino e aprendizagem do pessoa com Déficit de Atenção e Hiperatividade. No ambiente escolar e no 
ambiente familiar tem que existir uma harmonia, para que o trabalho que esteja sendo realizado pela escola não seja destruído dentro ambiente familiar, assim também que a escola possa colaborar com os pais informando o desenvolvimento do portador.

A Constituição Federal declara que a Educação é direito de todos e dever do Estado e da família e deverá ser promovida e incentivada com a colaboração da sociedade, visando o pleno desenvolvimento da pessoa, seu preparo para o exercício da cidadania e sua qualificação para o trabalho. (BRASIL, 1998, Cap III, seção I, do art. 205).

Uma questão que sempre surge na família que tem uma pessoa com TDAH é que deva ou não mudar a criança de escola. É uma questão muito comum quando os pais começam a perceber o transtorno no filho, os pais ao buscarem garantir a educação deles conforme exige a CF devem estar cientes de que boa parte da responsabilidade do desenvolvimento da criança não depende somente da escolas, se os mesmos não estiverem empenhados nesta causa, será desnecessário buscar as melhores escolas, se a família não acompanhar o processo de aprendizagem do sujeito com o transtorno e achar que a responsabilidade de ensinar seja somente da escola.

A escola é um importante e significativo agente socializador, já que amplia as possibilidades de aquisição de conhecimento e de experiência afetivas, na medida em que se configura como uma das primeiras situações instruídas, além, da família, a proporcionar experiências e desafios, constituindo-se assim em um espaço privilegiado para o desenvolvimento infantil.( BARKLEY, 2002).

Enquanto escola deve estar preparada para acolher e incluir a todos que chegam, a escola deve estar preocupada em realmente desenvolver o aprendizado de cada aluno, com comprometimento na formação dos professores, na sua metodologia de ensino, na diversidade de avaliação do aluno, ter cuidado com o número de alunos por turmas, e buscando trazer sempre a família para escola. A escola que tem a visão do desenvolvimento dos seus alunos pode realizar seminários de orientações para os pais que muitas vezes estão inconscientes de como este transtorno pode afetar a vida adulta da criança.

Lembrando sempre que a escola tem o papel de ensinar, mas, a família mais do que ninguém pode e deve educar desde cedo a trabalhar os limites, as regras que a pessoa com TDAH desconhece e muitas vezes age de forma impulsiva e inconsciente. 
Por fim, considerando-se a realidade educacional, fica claro a importância da intervenção da família e da escola que precisam estar entrelaçados neste processo, assim, certamente trará mais resultados efetivos em longo prazo, minimizando os efeitos decorrentes do TDAH.

\section{Conclusões}

No decorrer da pesquisa evidenciou-se que o TDAH é realmente um transtorno e que precisa ser tratado e acompanhado por diversos profissionais, iniciando pela família e seguido pela escola e todos os profissionais que possa contribuir no desenvolvimento do aprendizado do aluno com TDAH.

Percebeu-se que o sujeito com o transtorno tem capacidades de aprender, desde que o conhecimento lhe seja apresentado de forma dinâmica, de forma que consiga manter a sua atenção e concentração, e neste caso, o professor tem a sua maior responsabilidade em fazer com que esta criança consiga acompanhar a metodologia de ensino.

Constatou-se que o indivíduo com TDAH merece respeito e cuidados para que ao invés de fazer com que este se sinta menos inteligente que os outros, e futuramente ter um fracasso escolar, ele consiga ter um autocontrole através da disciplina e possa evoluir o seu lado intelectual.

Identificou-se que pouco ainda se conhece sobre o Transtorno de Déficit de Atenção e Hiperatividade dentro das escolas, e muitas instituições conhecem, mas não investigam mais sobre o transtorno e nem trabalham com o aluno de forma adequada. Mas por outro lado, constatou-se que sim, existem muitas escolas que já estão com o tratamento e espaço escolares próprios para trabalharem com o aluno com TDAH.

Percebeu-se que é importante a parceria entre escola e família para que o tratamento do TDAH ocorra dentro de casa assim como na escola de forma adequada e satisfatória para todos que acompanham o sujeito.

Ressalta-se que, em respeito pelo ser humano, as escolas possam observar mais quais os tipos de alunos que estão recebendo e busque aplicar uma metodologia de ensino capaz de garantir a formação de todos que chegam ao estabelecimento de ensino. 


\section{Referências}

AMORIM, Cacilda. O TDAH tem cura? Disponível em ttps://dda deficitdeatencao.com.br/ artigos/tdah-tem-cura.html

BARCKEY, Russeal. Transtorno de Déficit de Atenção/Hiperatividade(TDAH). Porto Alegre: ARTMED 2002

. ADHD and the nature of self-control. New York: The Gilford Press, 1997.

. History. In: Attention Deficit Hyperactivity Disorder: A handbook for diagnosis and treatment. Guilford Press, 1998, 3 - 55.

BEATRIZ, Ana Beatriz B. Silva. Mentes Inquietas. Rio de Janeiro:OBJETIVA LTDA,2009

BENCZIK, Edyleine Bellini Peroni. Transtorno de Deficit de Atenção/Hiperatividade : Atualização diagnóstica e terapêutica. São Paulo: Casa do Psicólogo, 2002.

BROWN, TE. Transtorno de Déficit de atenção. Porto Alegre.2007

CLASSIFICAÇÃO INTERNACIONAL DE DOENÇAS (CID - 10). Organização Mundial de Saúde, Universidade de São Paulo, 1994.

DSM-IV-TRTM. Manual diagnóstico e estatístico de transtornos mentais, $4^{\mathrm{a}}$ ed. Rev. Porto Alegre: Artmed, 2002.

DSM-V,AMERICAM PsychatrickAssociaton- Manual de diagnóstico e estatístico de distúrbios mentais. $5^{\circ}$ Ed. Editora Artes Medicas

DUPAL, STONER, George J. Dupaul,Gary Stoner. TDAH nas escolas. SãoPaulo: M. BOOKS.2007.

FILHO, Dinizar de Araújo. Entrevista: Hiperatividade. Petrópolis. 2003.

MATTOS, Paulo. No Mundo da Lua. ASSOCIAÇÃO BRASILEIRA DÉFICIT DE ATENÇÃO,2007.

PANTOJA, D. O Processo de Aprendizagem: A Construção do Conhecimento. In: WAJNSZTEJN, R. Dificuldades escolares: um desafio superável. São Paulo: Editora Ártemis, 2005.

PHELAN, T. W. - TDA/TDAH - Transtorno de Déficit de Atenção e Hiperatividade: Sintomas, Diagnósticos e Tratamento, São Paulo, M. Books do Brasil Editora LTDA, 2005.

ROHDE, LUIS \& HALPERN, RICARDO. Transtorno de déficit de atenção/hiperatividade: atualização. Jornal de Pediatria, v. 80, n. 2, Abril 2004. 
SILVIA MARIA, Ciasca, Transtorno do TDAH, Unicamp

TONELOTTO JM. Aspectos Acadêmicos e sociais do Transtorno de Deficit de Atenção e Hiperatividade. São Paulo: Casa do Psicologo,2003

\section{Como citar este artigo (Formato ABNT):}

BENÍCIO, Cineide M.; MENEZES, Aurelania M. de C. Transtorno do Deficit de Atenção e Hiperatividade - TDAH: Desafios e Possibilidades no Espaço Escolar. Id on Line Revista Multidisciplinar e de Psicologia, 2017, vol.11, n.38, p. 375-387. ISSN: 1981-1179.

Recebido: 30.10 .2017

Aceito: 31.10 .2017 